\title{
SINGING ACCENT AMERICANISATION IN THE LIGHT OF FREQUENCY EFFECTS: LOT UNROUNDING AND PRICE MONOPHTHONGISATION IN FOCUS
}

\author{
MONIKA KONERT-PANEK \\ University of Warsaw \\ m.konert@uw.edu.pl
}

\begin{abstract}
The paper investigates - within the framework of usage-based phonology - the significance of lexical frequency effects in singing accent Americanisation. The accent of Joe Elliott of a British band, Def Leppard is analysed with regard to LOT unrounding and PRICE monophthongisation. Both auditory and acoustic methods are employed; PRAAT is used to provide acoustic verification of the auditory analysis whenever isolated vocal tracks are available. The statistical significance of the obtained results is verified by means of a chisquare test. In both analysed cases the percentage of frequent words undergoing the change is higher compared with infrequent ones and in the case of PRICE monphthongisation the result is statistically significant, which suggests that word frequency may affect singing style variation.
\end{abstract}

Keywords: frequency effects, LOT unrounding, popular music, PRICE monophthonggisation, singing accent, usage-based phonology

\section{Introduction}

The phenomenon of style-shifting involved in pop singing in general and the Americanisation of British singing accent in particular have been investigated from various theoretical perspectives (Trudgill 1983, Simpson 1999, Beal 2009, Gibson and Bell 2012 among others). Depending on the theoretical standpoint, the notions of identity, reference style or default accent have been brought to light and assigned major explanatory power. Trudgill (1983) in his seminal paper on the sociolinguistics of British pop-song pronunciation interprets the emulation of the American accent as a symbolic tribute to the origins of popular music and provides the list of six characteristic features of this stylisation (1), two of which ((1c) and (1d)) are addressed in the present paper. 
a. coda-r: $\varnothing(\mathrm{Br}) \rightarrow[\mathrm{r}](\mathrm{Am})$ in non-prevocalic contexts (girl, far)

b. the (lack of) BATH-TRAP split: [a:] (Br) $\rightarrow$ [æ] (Am) before some fricative and nasal consonants (a non-systematic process) (can't, pass)

c. the LOT vowel unrounding: $[\mathrm{p}](\mathrm{Br}) \rightarrow[\mathrm{a}](\mathrm{Am})($ hot $)$

d. monophthongisation of the PRICE diphthong: [aI] (Br) $\rightarrow$ [a:] (Southern Am) (my)

e. flapping: $[\mathrm{t}](\mathrm{Br}) \rightarrow[\mathrm{r}](\mathrm{Am})$ intervocalically before an unstressed vowel (better)

f. the STRUT vowel raising: $[\Lambda](\mathrm{Br}) \rightarrow[$ [ə] (Am) (cut, won)

A number of questions regarding the character of the abovementioned variation, as well as the details of its mechanisms call for further research. One of them concerns the reason why some phonetic features seem to be more prone to Americanisation. Another matter, to some extent connected with the previous one, is distinct behaviour of various words exhibiting the feature at stake within a given phonetic process, the phenomenon that may be considered with the reference to lexical frequency effects.

The dynamics of variation and style shifting acquires a central position in the usage-based paradigm (Bybee 2001), represented as an exemplar model (Johnson 1997, Pierrehumbert 2001). In this model, tokens of linguistic experience are stored together with contextual information, including pragmatic and social or cultural indexation. Thanks to rich lexical representation and automatic associations created and stored in memory, individuals have access not only to the semantic layer, but also to the layer of speakers' identity indices (Foulkes and Docherty 2006). Thus, with regard to the phenomenon of singing accent stylisation, tokens that are indexed as "American" are activated in relevant sociocultural contexts. Frequency of use also assumes a prominent position in an exemplar theory, in which "a token of linguistic experience that is identical to an existing exemplar is mapped onto that exemplar, strengthening it" (Bybee 2006: 716); hence, the more frequent a given word is, the more it is entrenched in a speaker's lexicon.

The very observation that frequent words behave differently from infrequent ones is not new - their tendency to change faster was already noticed by Schuchardt (1885), with numerous successive studies providing further examples of the phenomenon. Frequent words tend to be processed faster, recognized quicker and articulated more easily (e.g. Bybee 2002, Shockey 2003, Erker and Guy 2012). They are also known to lead in a number sound changes, mainly favouring phonetic reduction, e.g. schwa deletion, as well as final [t] and [d] deletion are more common in highly frequent words (Hooper (Bybee) 1976, Bybee 2000, respectively), the Dublin Vowel Shift first affected frequent words (Hickey 1998), lexical frequency also influenced the rate of [ar] monophthongisation in the study on Oprah Winfrey style-shifting (Hay, Jannedy and Mendoza-Denton 1999). 


\section{The analysis}

\subsection{Research aims}

The aim of this paper is to estimate - within the framework of usage-based phonology, in which sociophonetic variation occupies a central position - the potential significance of lexical frequency effects: to assess whether more frequent words prove to be the carriers of Americanised singing style, still observable in British popular music. In order to do this, the singing accent of Joe Elliott of a British hard-rock band Def Leppard is examined with regard to two processes: LOT unrounding and PRICE monophthongisation. Additionally, a certain problem regarding the status PRICE monophthongisation as such is addressed. As this process may be perceived as Americanisation or just general casual speech reduction, the quantitative comparison of the vocalist's singing vs. speaking styles is conducted to ascertain the nature of the process.

\subsection{Def Leppard: general background}

Def Leppard is a hard rock British band, whose vocalist, Joe Elliott, was born in Sheffield, Yorkshire, in 1959. The group, active since 1977, is one of the world's best-selling music artists, having achieved outstanding success on the American music market, with their two studio albums (Pyromania 1983 and Hysteria 1987) selling over ten million copies and thus being awarded diamond by the Recording Industry Association of America (RIAA) - an accomplishment celebrated by only six rock bands so far. ${ }^{1}$

Def Leppard's fascination with America can already be noticed on their debut album, On Through the Night (1980). In the song entitled simply "Hello America" they fantasize about touring in the US:

Well I'm takin' me a trip I'm going down to California

Yeah, I'm gonna try Hollywood and San Pedro Bay

I'll tell ya what I'm gonna do

I'm gonna give my love to you

I'm gonna take you where the lights are bright

I'm gonna give you my love tonight

Hello America, hello America

Hello America, hello America

"Hello America" (On Through the Night 1980)

https://www.riaa.com/gold-platinum/?tab_active=awards_by_artist\&col=diamond_units\&ord= desc\#search_section [Accessed: $18^{\text {th }}$ February 2018]. 
The vocalist describes the context in which he wrote the song, juxtaposing gloomy Yorkshire surroundings with the bright visions of America:

We had never even been to America at that point. I was working in a factory with lots of nuts and bolts and no natural light. But there was a lot of downtime, and I would sit around writing stuff. With this one, I had seen a TV show the night before - Kojak or Starsky \& Hutch, something where they show the tree-lined boulevards of L.A. You see all these palm trees and you go, "Wow, this is a lot sexier than Sheffield!" That's where that lyric came from - "Well I'm takin' me a trip/I'm going down to Californ-i-a." It was, "Get me out of here!".2

Thus, it may be unsurprising that Elliott's singing style reflects the abovementioned fascination. Def Leppard's exceptionally heavy Americanisation is even noticed by other singers, e.g. Robert Smith of The Cure:

I despise Def Leppard and everything they've ever done. I can't believe how popular Def Leppard are. It sickens me to see them all sitting there in Union Jacks and yet [Def Leppard singer, Joe Elliott] adopts that horrible, fake, rock-American accent. ${ }^{3}$

The members of Def Leppard are fully aware of their style-shifting. Def Leppard's guitarist, Phil Collen, comments on their singing style as follows:

"People always used to ask why we sound like Americans," says Def Leppard guitarist Phil
Collen from a shed tour stop along the outskirts of the country's northern border in Walker,
Minnesota. "Because that is how we learned to be musicians," he answers. "I wish they all
could be California girls," Collen sings through the phone as he polishes off a rendition of a
Beach Boys' benchmark. "It is an American accent before you know it. We learned it that
way because the stuff happening in England wasn't really homegrown. The pop music was
American based blues and R\&B. It had a hook to it, it was sexy, and it was the whole Elvis
thing". 4

Some examples of Def Leppard's Americanised singing style with regard to the LOT and PRICE vowels are given below. As it may be noticed, this stylisation goes in line with very straightforward rock message (in Joe Elliott's own words, they do "simplistic, anthemic rock and roll"5):

2 http://www.rollingstone.com/music/lists/def-leppards-joe-elliott-my-life-in-15-songs20160322/bringin-on-the-heartbreak-1981-20160322 Bienstock, R. Def Leppard's Joe Elliott: My Life in 15 Songs. 22.03.2016 [Accessed: $18^{\text {th }}$ February 2018].

3 Considine, J.D. The concert's the thing you can keep the rest, says the Cure's front man. 24.05.1992. Available from: http://articles.baltimoresun.com/1992-05-24/features/1992145174 _1_cure-smith-fans/2 [Accessed: 18th February 2018].

4 http://www.theaquarian.com/2007/08/08/def-leppard-americas-brits/ Halo, M. Interview with Def Leppard: America's Brits. 08.08.2007 [Accessed: 18th February 2018].

5 https://www.youtube.com/watch?v=yaKjEhZ_wyg Metal Hammer Official. Def Leppard Interview - Joe Elliott. 12.01.2012 [Accessed: $18^{\text {th }}$ February 2018]. 
I got [gat] my [ma] whiskey,

I got [gat] my [ma] wine

I got [gat] my [ma] woman,

and this time the lights are going out

"High 'N' Dry (Saturday Night)" [High and Dry 1981]

Rock [rak] of ages, rock of ages

Still rollin', rock'n'rollin' [rak]

We got [gat] the power, got [gat] the glory

Just say you need it

and if you need it

Say yeah

"Rock of Ages" [Pyromania 1983]

Joe Elliott's speaking style is distinctly different, as it can be observed e.g. in the abovementioned interview. ${ }^{6}$ The qualitative and quantitative details regarding the LOT and PRICE vowels are presented in, respectively, sections 3.1 and 3.2, but the overall impression confirms the old split between singing and speaking styles of British vocalists noticed by Trudgill (1983): the variety Elliott adheres to is British (e.g. the rounded [p] in rock or everybody); his Northern origin can also be noticed, e.g. the lack of the FOOT-STRUT split in some words (country, stuff). Elliott's pronunciation of the PRICE diphthong is analysed in a quantitative detail in section 3.2, but the general impression is that he uses [aI] pronunciation, with no indications of potential monophthongisation to [a:], which confirms Beal's (2004: 125) description of the current status of the diphthong in the North of England: the monophthongisation of [aI] to [a:] is characteristic of more traditional dialects, while the majority of PRICE words are nowadays pronounced with a diphthong in this region. This makes PRICE monophthongisation a proper choice for the analysis of singing accent Americanisation.

Taking all the above into consideration, it seems that the case of Def Leppard constitutes an interesting object of study with regard to the main aim of this paper. The band itself is described as "the definitive hard rock band of the " $80 \mathrm{s"}$ " and the vocalist's singing accent may be treated as the representative of heavy Americanisation (observable in British pop singing style since the 1950s), providing ample data for the analysis. Finally, striking contrasts and conflicting identities are clearly visible, as his spoken accent is British, with some Northern features.

6 https://www.youtube.com/watch?v=yaKjEhZ_wyg Metal Hammer Official. Def Leppard Interview - Joe Elliott. 12.01.2012 [Accessed: $18^{\text {th }}$ February 2018].

7 https://www.allmusic.com/artist/def-leppard-mn0000193320/biography Erlewine, S. T. Artist Biography. [Accessed: $18^{\text {th }}$ February 2018]. 


\subsection{Materials and methodology}

The analysis is based on three studio albums by Def Leppard (about 7469 words): On Through the Night (1980), High ' $n$ ' Dry (1981), Pyromania (1983) and five isolated vocal tracks: "Rock of Ages", "Photograph", "Foolin"”, "Bringin' on the Heartbreak", "Undefeated" (the availability of high-quality isolated vocal tracks, which make acoustic analysis possible, is limited). Spoken accent analysis is based on a high-quality interview: "Def Leppard Interview - Joe Elliott Metal Hammer Official" (2012). ${ }^{8}$

Frequency was measured locally, i.e. the word frequency of the sample itself was used, following the methodology and argumentation given by Hay at al. (1999) and Erker and Guy (2012) regarding "the spirit of usage-based models" (Erker and Guy 2012: 530). All LOT and PRICE items in the corpora were identified as frequent (occurring 5 or more times) or infrequent (occurring fewer than 5 times). All surface word-forms were considered (not lemmas). The following elements were excluded from the analysis: backing vocals or other voices (the interviewer, the audience), spoken fragments in songs, triphthongs, function words in the case of the LOT vowel (except on), other LOT words with optional schwa (e.g. gonna), unless it was evident a given speaker uses either [p] or [a] (e.g. in anybody, somebody, nobody), as well as parts of the recordings of poor quality. The statistical significance of the obtained results regarding lexical frequency effects was verified by means a of chi-square test with Yates' correction.

A combination of auditory and acoustic methods was used for the analysis of the material. PRAAT was used to provide acoustic verification of the auditory analysis (on the basis of isolated vocal tracks and a selected interview). PRAAT script (pnwe_get_205080.praat script; Pacific Northwest English study (Wassink)) was used for both the LOT and PRICE vowels (the midpoint method and proportional distance method with measurements at $20 \%$ and $80 \%$ into the vowel, respectively).

Monophthongisation is a continuous feature, but for the sake of frequency count it has to be treated as a binary one. There are various methods of measuring this process. For the gathered data, the adopted approach - based on the methodology by Cramer (2016), with modifications - was as follows. First, the relative change of frequency (in percents) of both formants F1 and F2 ( $d f 1$ and $d f 2$, respectively) was measured: the frequency at $20 \%$ was subtracted from the frequency at $80 \%$ and the difference was divided by the frequency at $20 \%$.

8 https://www.youtube.com/watch?v=yaKjEhZ_wyg Metal Hammer Official. Def Leppard Interview - Joe Elliott. 12.01.2012 [Accessed: $18^{\text {th }}$ February 2018]. 
(2) Measurement of relative change in both formants' frequencies: relative change of frequency (percents): $d f 1, d f 2$
a. $d f 1=\frac{f 1_{80}-f 1_{20}}{f 1_{20}}$
b. $d f 2=\frac{f 2_{80}-f 2_{20}}{f 2_{20}}$

Next, the relative spread $(s)$ at $80 \%$, i.e. the sum of percentage changes of both formants' frequencies (in percentage points) was measured.

$$
\begin{aligned}
& \text { Relative spread at } 80 \% \text { (percentage points): } s \\
& \quad s=d f 2+d f 1
\end{aligned}
$$

A vowel was considered diphthongal if the relative spread equalled at least 25 percentage points or if at least one change of formant frequency was greater than $10 \%$. A vowel was considered monophthongal otherwise, i.e., if the relative spread was lower than 25 percentage points and both relative changes of formant frequencies equalled $10 \%$ or less, as monophthongisation could be achieved by a greater change of one formant or a moderate change of both formants.

PRAAT was used to verify the auditory analysis of the LOT items in isolated vocal tracks. All the elements were identified as "British" or "Americanised". The scatterplots present [p] vs. [a] frequencies of F1 and F2 (Figure 1 and Figure 2, respectively). Though extreme frequency values of $[\mathrm{p}]$ and $[\mathrm{a}]$ overlap, the scatterplots still enable to distinguish two clusters, forming two distinct vowel groups.

The F1 and F2 mean values, based on the analysis of 91 tokens, are given in Table 1. The acoustic analysis shows that both formants have higher frequencies compared with speaking. Regarding F1, this confirms the results of Gibson's (2010) study, in which it is shown that F1 is significantly higher in singing due to the sonority factor: the general preference for openness in this mode. 


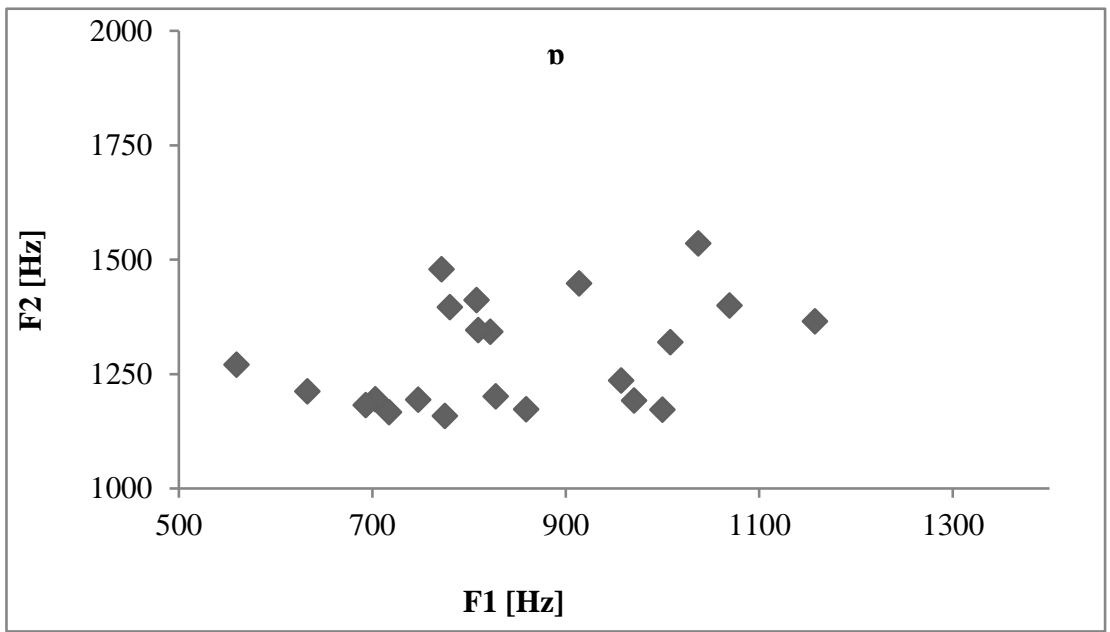

Figure 1. Joe Elliott's singing accent (isolated vocal tracks): the LOT vowel realized as [p]

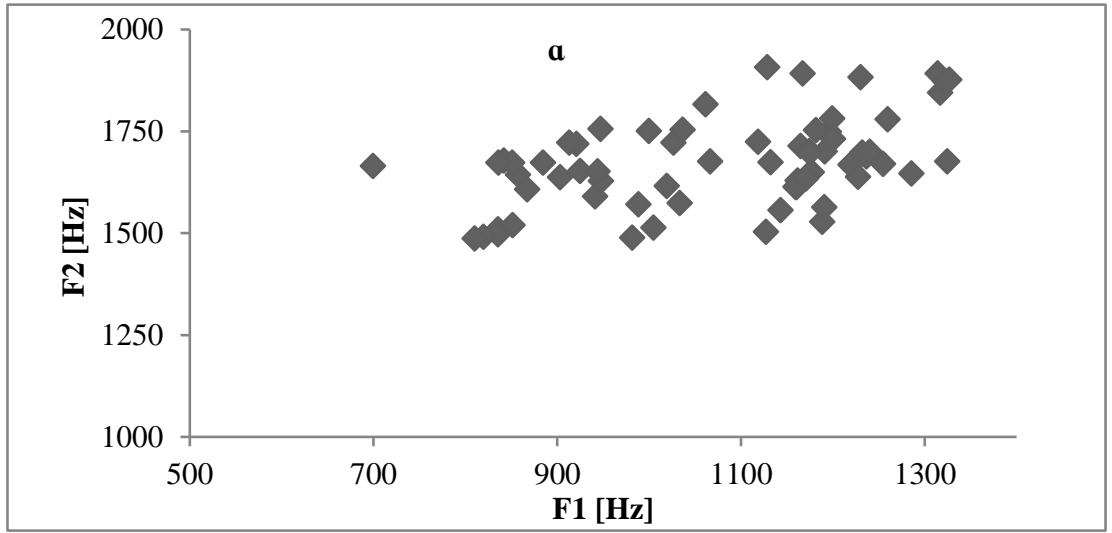

Figure 2. Joe Elliott's singing accent (isolated vocal tracks): the LOT vowel realized as [a]

Table 1. Joe Elliott's singing accent (isolated vocal tracks): the LOT vowel mean F1 and F2 values

\begin{tabular}{cccc}
\hline the LOT vowel & F1 mean & F2 mean & No. of tokens \\
\hline $\mathrm{D}$ & 795 & 1293 & 25 \\
$\mathrm{a}$ & 1078 & 1674 & 66 \\
\hline
\end{tabular}


Figure 3 and Figure 4 show the trajectories of the PRICE vowel realized, respectively, as a monophthong (31 analysed tokens) and a diphthong (21 analysed tokens), i.e. the mean values of $\mathrm{F} 1$ and $\mathrm{F} 2$ measured at 5 time points across the vowel. Figure 5 constitutes a comparison of the average trajectories of [a] and [ar].

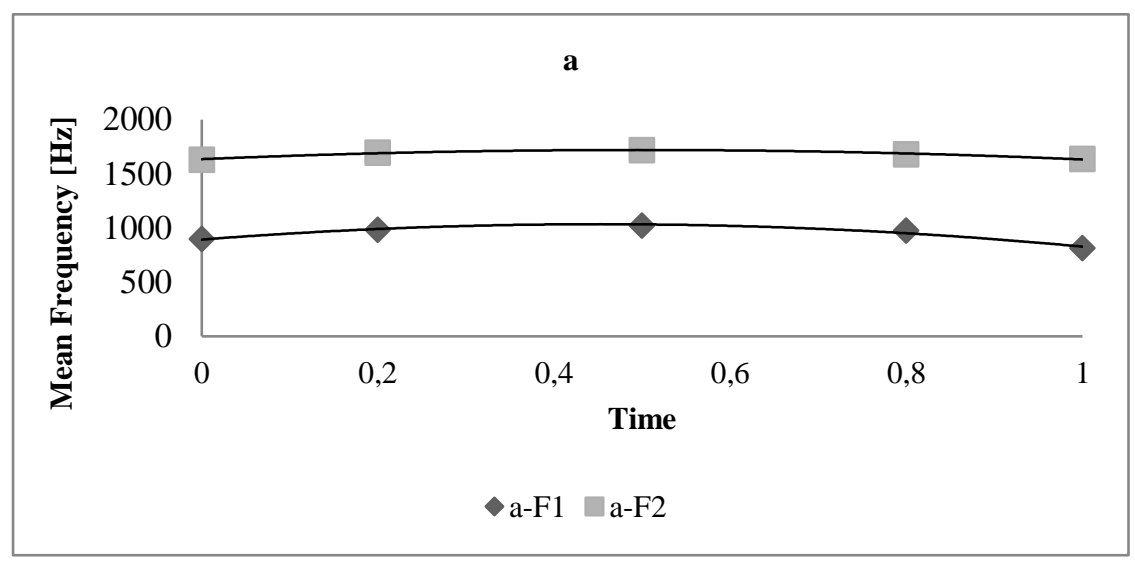

Figure 3. Joe Elliott's singing accent (isolated vocal tracks). The trajectory of the PRICE vowel realized as a monophthong: the mean values of $\mathrm{F} 1$ and $\mathrm{F} 2$ at 5 time points across the vowel

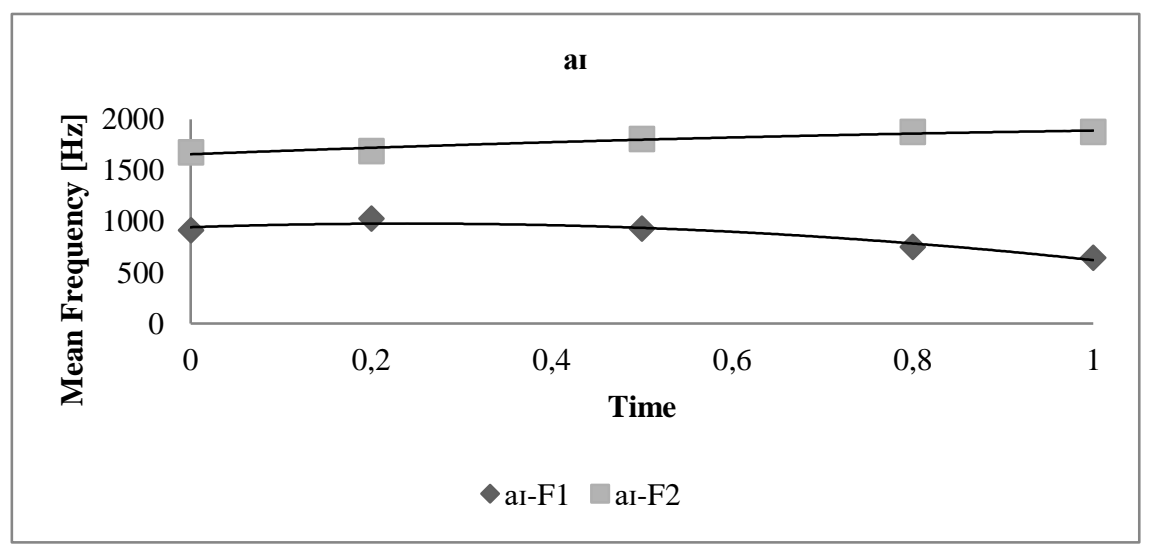

Figure 4. Joe Elliott's singing accent (isolated vocal tracks). The trajectory of the PRICE vowel realized as a diphthong: the mean values of F1 and F2 at 5 time points across the vowel 


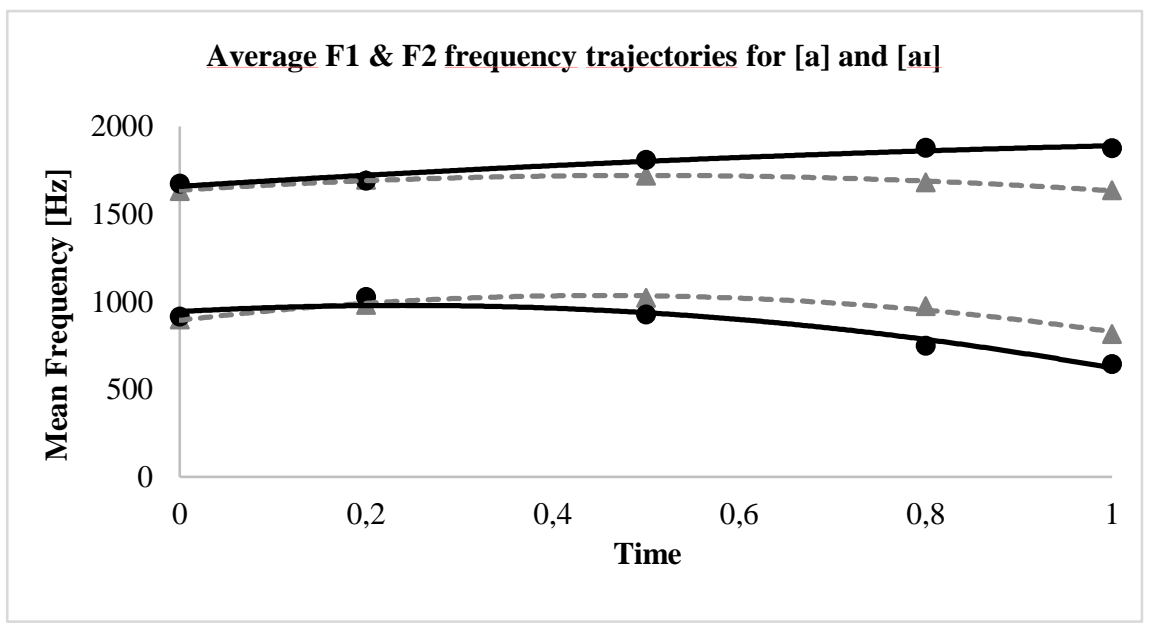

Figure 5. Joe Elliott's singing accent (isolated vocal tracks): average F1 and F2 frequency trajectories of [a] (triangles and dotted lines) and [ar] (circles and solid lines)

\section{Results}

\subsection{Spoken accent: the LOT vowel}

With regard to the speaking mode, the acoustic analysis confirms auditory impressions - there is no Americanisation in this respect, all analysed tokens are rounded ([p]). The mean F1 and F2 values, based on 26 analysed tokens, are: 569 $\mathrm{Hz}$ and $939 \mathrm{~Hz}$, respectively. The values are comparable to the ones given in literature, e.g. Hawkins and Midgley (2005).

\subsection{Spoken accent: the PRICE diphthong}

The PRICE diphthong was generally pronounced as [aI]; it was monophthongised in the speech of the vocalist in only $17 \%$ of cases (5 tokens out of 30 analysed acoustically).

\subsection{Singing accent: lexical frequency and LOT unrounding}

The results of lexical frequency effects analysis given in Table 2 show that frequent words favoured unrounding, though the difference is relatively small (60\% vs. 52\%), with the overall degree of Americanisation in the corpus reaching $59 \%$. 
Table 2. Joe Elliott's singing accent: lexical frequency and LOT unrounding

\begin{tabular}{cccc}
\hline frequency level & $\mathbf{a}$ & $\mathbf{p}$ & total \\
\hline frequent & $224(60 \%)$ & 152 & 376 \\
infrequent & $32(52 \%)$ & 29 & 61 \\
total & $256(59 \%)$ & 181 & 437 \\
\hline
\end{tabular}

In order to check the statistical significance of the obtained results, a chi-square test with Yates' correction was conducted. On the basis of the distribution of all 437 tokens (54 types) in the corpus, as presented in Table 2, it turns out frequent words are not significantly more likely to undergo LOT unrounding (Yates' chisquare $=0.822, \mathrm{df}=1, \mathrm{p}=<0.36$ ).

\subsection{Singing accent: lexical frequency and PRICE monophthongisation}

With regard to PRICE monophthongisation, the analysis shows that frequent words favoured the process and this difference is greater compared with the previous one (see Table 3). In Elliott's singing style 52\% of frequent words and $23 \%$ of infrequent ones undergo the process. The overall degree of Americanisation in this respect reaches $43 \%$.

Table 3. Joe Elliott's singing accent: lexical frequency and PRICE monophthongisation

\begin{tabular}{cccc}
\hline frequency level & a & aI & total \\
\hline frequent & $170(52 \%)$ & 158 & 328 \\
infrequent & $31(23 \%)$ & 106 & 137 \\
total & $201(43 \%)$ & 264 & 465 \\
\hline
\end{tabular}

In order to check the statistical significance of the obtained results, a chi-square test with Yates' correction was conducted. On the basis of the distribution of all 465 tokens (99 types) in the corpus, as presented in Table 3, it turns out frequent words are significantly more likely to undergo PRICE monophthongisation (Yates' chi-square $=32.399, \mathrm{df}=1, \mathrm{p}<0.00000001$ ).

\section{Discussion and conclusions}

The main research aim was to assess the significance and potential explanatory role of lexical frequency effects in singing accent stylisation, namely, to evaluate whether highly frequent words prove to be the best carriers of Americanised singing style. In general, the outcome seems to be promising, as in both analysed processes the percentage of frequent words undergoing the change was higher compared with infrequent ones. The results suggest that word frequency can affect variation, as common words facilitate PRICE monophthongisation - they are 
significantly more likely to undergo the process. However, as regards LOT unrounding, in the case of which the difference was not statistically significant, further research is required to establish precisely the potential significance of lexical frequency effects. In particular, including more types of analysed LOT words in a bigger corpus may be revealing.

As regards the additional research question, i.e. the potentially problematic status of PRICE monophtongisation, the analysis shows that the process is encountered in Joe Elliott's speech, yet the percentage is small in comparison with his singing accent (17\% and $43 \%$, respectively). Thus, taking into account his general style in both analysed modes and the comparative degree of monophthongisation, one may venture to say that in this case the contrast may indeed indicate Americanisation, rather than casual speech reduction. What may be emphasised, though, is the importance of a quantitative account with regard to the speaking mode to evaluate the overall comparative degree of monophthongisation, as the results may be quite different for other vocalists.

Finally, it seems vital to stress that frequency does not function in isolation. Rather, it is interrelated with other phenomena, which - when combined - could add to the explanatory power of the analysed factor alone. Naturally, frequency and experience are intrinsically connected. Frequency is a reflection and derivative of experience, as Bybee (2006: 711) points out, describing the usagebased perspective: "grammar is the cognitive organization of one's experience with language". Among the totality of one's experiences there are these special inspirations, which prove to be of particular significance in the music world. This is visible at the personal, individual level of various artists, while delving into their biographies, e.g. British musicians as stylistically distant as the glam rock icon David Bowie and Dizzee Rascal, a grime artist, both known for their use of British accent in singing, point to, respectively, Syd Barrett, and UK garage or drum and bass MCs as their inspirations in this respect. ${ }^{910}$

9 "He [Syd Barrett] was the first guy I'd heard to sing pop or rock with a British accent - his impact on my thinking was enormous. [David Bowie]" http://www.nme.com/news/music/pinkfloyd-128-1366035

David Bowie pays tribute to Syd Barrett. 11.07.2006. [Accessed: $18^{\text {th }}$ February 2018].

10 "Drum and bass MCs (...), UK garage MCs (...) influenced me as much as American hip-hop. I already wanted to sound like where I was from." https://www.youtube.com/watch?v=ARMZBxGKlG4 Vlad TV. Dizzee Rascal: I Believe Ali G Character Was Based Off Tim Westwood. 13.05.2016. [Accessed: $18^{\text {th }}$ February 2018]. 
Inspiration then seems to be key. However, this phenomenon may also be transferred to a more general level: to the plane of tendencies and fashions in the music industry. It could be compared, to quote Joe Elliott again, to passing the torch ${ }^{11}$ in singing - in this case, the accent torch. In the usage-based paradigm there is place for such changes, the system is mutable, dynamic, never fixed. Memories may remain or decay and the well-known elements of the system may be reshaped to create novel modes of expression and become acts of identity in new circumstances.

\section{References}

Beal, Joan. 2004. English dialects in the North of England: phonology. In Bernd Kortmann and Edgar W. Schneider (eds.), A Handbook of Varieties of English. Volume 1: Phonology, 113-123. Berlin and New York: Mouton de Gruyter.

Beal, Joan. 2009. "You're not from New York City, you're from Rotherham": Dialect and identity in British indie music. Journal of English Linguistics 37 (3). 223-240.

Boersma, Paul and David Weenink. 2016. Praat: Doing Phonetics by Computer [Computer program]. Version 6.0.14, [Online]. Available from: http://www.praat.org/.

Bybee, Joan. 2000. The phonology of the lexicon: evidence from lexical diffusion. In Michael Barlow and Suzanne Kemmer (eds.), Usage-based models of language, 65-85. Stanford, CA: CSLI.

Bybee, Joan. 2001. Phonology and language use. Cambridge: Cambridge University Press.

Bybee, Joan. 2002. Word frequency and context of use in the lexical diffusion of phonetically conditioned sound change. Language Variation and Change 14. 261-290.

Bybee, Joan. 2006. From Usage to Grammar: The Mind's Response to Repetition. Language 82 (4). 711-733.

Cramer, Jennifer. 2016. Rural vs. urban: Perception and production of identity in a border city. In Jennifer Cramer and Chris Montgomery (eds.), Cityscapes and Perceptual Dialectology, 27-54. Berlin: Mouton de Gruyter.

Erker, Daniel and Gregory R. Guy. 2012. The role of lexical frequency in syntactic variability: Variable subject personal pronoun expression in Spanish. Language 88 (3). 526-557.

Foulkes, Paul and Gerard Docherty. 2006. The social life of phonetics and phonology. Journal of Phonetics 34. 409-438.

Gibson, Andy. 2010. Production and Perception of Vowels in New Zealand Popular Music, MPhil thesis, Auckland University of Technology.

Gibson, Andy and Allan Bell. 2012. Popular Music Singing as Referee Design. In Juan M. Hernández-Campoy and Juan A. Cutillas-Espinosa (eds.), Style-Shifting in Public. New Perspectives on Stylistic Variation, 139-164. Amsterdam: John Benjamins Publishing Company.

Hawkins, Sarah and Jonathan Midgley. 2005. Formant frequencies of RP monophthongs in four age groups of speakers. Journal of the International Phonetic Association 35 (2). 183-199.

Hay, Jennifer, Stefanie Jannedy and Norma Mendoza-Denton. 1999. Oprah and /ay/: lexical frequency, referee design and style. Proceedings of the $14^{\text {th }}$ International Congress of Phonetic Studies. San Francisco August 1999. 1389-1392.

11 https://www.youtube.com/watch?v=yaKjEhZ_wyg Metal Hammer Official. Def Leppard Interview - Joe Elliott. 12.01.2012 [Accessed: $18^{\text {th }}$ February 2018]. 
Hickey, Raymond. 1998. The Dublin Vowel Shift and the historical perspective. In Jacek Fisiak and Marcin Krygier (eds.), Advances in English Historical Linguistics (1996), 79-106. Berlin: Mouton de Gruyter.

Hooper, Joan. 1976. Word frequency in lexical diffusion and the source of morphophonological change. In William Christie (ed.), Current Progress in Historical Linguistics, 96-105. Amsterdam: NorthHolland.

Johnson, Keith. 1997. Speech perception without speaker normalization: An exemplar model. In Johnson Keith and John Mullennix (eds.), Talker Variability in Speech Processing, 145-165. San Diego: Academic Press.

Pierrehumbert, Janet B. 2001. Exemplar dynamics: Word frequency, lenition, and contrast. In Joan Bybee and Paul Hopper (eds.), Frequency effects and the emergence of lexical structure, 137-157. Amsterdam: John Benjamins Publishing Company.

Schuchardt, Hugo. 1885. Über die Lautgesetze. Gegen die Junggrammatiker. Berlin: Oppenheim.

Shockey, Linda. 2003. Sound Patterns of Spoken English. Oxford: Blackwell Publishing.

Simpson, Paul. 1999. Language, Culture and Identity: With (another) look at accents in pop and rock singing, Multilingua 18(4). 343-367.

Trudgill, Peter. 1983. Acts of Conflicting Identity. The Sociolinguistics of British Pop-Song Pronunciation. In Peter Trudgill (ed.), On Dialect. Social and Geographical Perspectives, 141-160. Oxford: Blackwell. 